\title{
Ensino de Psicologia
}

WITTER, C. (org) (1999). Ensino de Psicologia. Campinas: Editora Alínea, 204p

A presente obra foi organizada pela Professora Doutora Carla Witter, que realiza pesquisas na área de Psicologia Escolar, meios de comunicação de massa e produção científica. A obra compõe a Coleção Psicotemas que tem por objetivo viabilizar o acesso da produção científica na área de Psicologia.

O livro em suas 204 páginas contém um prefácio assinado pela organizadora da obra, no qual discute os aspectos relevantes sobre as pesquisas na área de ensino de Psicologia, coloca que a obra é resultado do trabalho de pesquisadoras brasileiras através de dissertações de mestrado e teses de doutorado, defendidas nos programas de Pós-Graduação da PUC-Campinas da USP. A obra está estruturada em duas grandes partes nas quais estão agrupados textos teóricos e textos de pesquisa.

A primeira parte enfoca temas sobre a formação do psicólogo de um modo geral, sobre o papel da pesquisa na formação do psicólogo; situa a Psicologia Escolar no exterior, além de tratar da formação e atuação do psicólogo escolar; e de questões sobre a relevância da Psicologia Educacional na formação de professores.

Na segunda parte da obra estão agrupados os textos de pesquisas, que por sua vez investigaram as atividades de pesquisas realizadas em um curso de Psicologia, a problemática da Psicologia Escolar e a produção científica; a formação e o estágio em Psicologia Escolar e, por fim, os aspectos sobre a formação em Psicologia Clínica.

De modo geral, os textos apresentam uma bibliografia variada e atualizada, em que são indicadas diversas fontes, como teses, dissertações, artigos de pesquisa nacionais e internacionais.

Yukimitsu (1997), doutora em Psicologia Escolar e desenvolvimento humano pela USP, e professora universitária, assina o Capítulo 1 da obra com o título A formação do psicólogo: considerações gerais, no qual discute aspectos estruturais de um currículo para formação de psicólogos, passando pelas questões sobre a responsabilidade social, ética, cultura, sociedade e as implicações destas para a formação do psicólogo, além da relevância do ensino de pesquisas como fator norteador de novas mudanças para uma formação mais sólida.

Com isso, a autora apresenta uma relevante discussão sobre a importância e necessidade de se adotar efetivamente uma formação mais generalista pautada em princípios éticos e de uma sólida base teórica, e de prática de pesquisa. Sendo tais aspectos potencializados através do acesso a recursos essenciais como corpo docente e bibliotecas.

No Capítulo 2, Natário (1994) descreve inúmeros aspectos que fundamentam a importância e a necessidade do ensino e da prática de pesquisa para formação do psicólogo. A autora tece uma interessante discussão sobre a relevância do ensino de pesquisa para formação em Psicologia, e apresenta as diferenças de enfoques de pesquisas existentes em outros países com o contexto nacional.

Tal discussão repercute por sua vez em aspectos que vão desde o caráter de valorização cultural da pesquisa até as implicações para o desenvolvimento do conhecimento. A autora discute e defende atividades de alfabetização científica como uma estratégia para o melhor desenvolvimento científico/tecnológico, seja em nível individual, como por exemplo, para um profissional de Psicologia, seja em nível maior, como o próprio desenvolvimento científico de um país.

Discute ainda, os aspectos do o ensino de pesquisa na formação em Psicologia, que muitas 
vezes deixa a desejar, uma vez que não se percebe uma definição clara e sólida sobre o papel e importância do ensino de pesquisa, e sim um contexto inadequado no ensino de tal atividade, que resulta em compreensão errônea tanto no que diz respeito à atividade de pesquisa em si, como quanto a importância social que representa a pesquisa científica.

Tais capítulos podem, com toda certeza, serem utilizados como um grande recurso para discussões sobre a relevância da pesquisa tanto para vida profissional como para o desenvolvimento da própria Psicologia, principalmente em disciplinas de metodologia de pesquisa, ministradas nos primeiros semestres dos cursos de Psicologia, momento em que os alunos estão começando a desenvolver sua identidade profissional.

Gonçalves (1999) discorre sobre a Formação em Psicologia Escolar no exterior e no Brasil (Capítulo 3) realizando uma interessante caracterização da Psicologia Escolar nas perspectivas internacional e nacional. Destaca as diferenças na formação e atuação desta profissão em cada um dos contextos, sempre levando em consideração os diferentes estágios de desenvolvimento científico e profissional presentes nos distintos contextos. Este capítulo pode ser caracterizado como um importante texto a ser utilizado em cursos de graduação e pós-graduação, uma vez que proporciona uma interessante visão sobre as abrangências da Psicologia tanto no campo profissional como no científico.

Witter (1996) apresenta grande contribuição no Capítulo 4, ao estabelecer uma discussão sobre diversos aspectos pertinentes a formação e atuação do psicólogo escolar. A autora reuniu trabalhos de diferentes nacionalidades e delineamentos metodológicos. No entanto, verificou a ausência de pesquisas experimentais, bem como uma publicação e/ou base de dados específica para a área, o que possibilitaria o melhor acompanhamento sobre as atividades realizadas na área.

Compondo o último dos textos teóricos a Psicologia Educacional na formação de professores (Capítulo 5), Foresti (1994) apresenta uma discussão sobre a importância e a contribuição que o conhecimento psicológico pode proporcionar ao professor, como suporte técnico através de estratégias de ensino, compreensão do desenvolvimento humano, teorias de aprendizagem, chegando a discutir a aplicação destes na prática do professor.

Outro enfoque interessante adotado pela autora, refere-se às pertinentes discussões sobre as atividades, papéis e responsabilidades que o docente de Psicologia Educacional desempenha na formação dos futuros professores.

Com isso, este capítulo teria uma grande utilidade se utilizado como texto de apoio em disciplinas de cursos de Magistério (nível médio) ou de Pedagogia e Psicologia. Poderia ser um fonte de discussões sobre a importância da Psicologia para a formação docente, ou até mesmo em cursos de pós-graduação, para uma discussão sobre papéis e responsabilidades dos docentes em Psicologia ou ainda de Psicopedagogia.

Iniciando a segunda parte da obra com os textos de pesquisa, Natário (1994), no Capítulo 6, discorre sobre concepções e experiências de alunos de um curso de Psicologia sobre suas atividades de pesquisa, contrapondo com variáveis apresentadas pelos próprios sujeitos como contribuintes ou não para participação em atividades de pesquisa durante os anos de graduação; a autora discute se as condições oferecidas pela universidade são, na opinião dos sujeitos, favoráveis ou não às atividades de pesquisa. Uma questão importante, refere-se à prudência adotada pela autora ao lembrar que os dados encontrados na pesquisa não poderiam ser totalmente considerados, uma vez que a estrutura do curso foi alterada nestes últimos anos, modificando com isso o contexto de 
inserção da pesquisa no curso de Psicologia da instituição estuda.

Para tratar sobre a "Psicologia Escolar e produção científica", Witter (1996) apresenta um interessante quadro sobre a produção científica nesta área. A autora realizou um estudo em periódicos e anais nacionais da área de Psicologia Escolar. Os principais resultados, apontam para uma triste realidade em que os periódicos não chegam a publicar um artigo por mês, evidenciando com isso que no atual contexto nacional, para a produção de pesquisa em Psicologia Escolar, não se utiliza de todo seu potencial, o que evidencia uma clara dificuldade em atender às necessidades sociais em tomo das problemáticas da Psicologia Escolar.

A autora pondera ainda, sobre os fatores que poderiam estar contribuindo para esta baixa produção, como dificuldade de divulgação de trabalhos, entraves financeiros; por outro lado, indica que as publicações em anais da área, apresentaram-se como o veículo mais apropriado para a disseminação de conhecimentos, e com isso talvez mais adequado às necessidades e realidades sociais, bem como a própria natureza deste, geralmente decorrentes de encontros de profissionais da área, como que um espaço legitimado para troca de informações.

Gonçalves (1994) em seu capítulo "Formação geral e estágio acadêmico em Psicologia Escolar" enfoca, de modo instigante, a inserção de aspectos relacionados ao estágio na área, através de uma análise curricular de instituições de formação de psicólogos. Obteve resultados que indicam que grande parte das mudanças curriculares em cursos de Psicologia ocorreu na área clínica; já para as atividades de estágio obteve-se maior índice de mudanças em aspectos estruturais do estágio, sendo que a Psicologia Escolar apresentou-se, de certa forma, um pouco mais beneficiada, apesar de uma tendência de unificação com os estágios em clínica.

Por fim, concluindo a parte sobre os textos de pesquisa, Yukimitsu (1997) trata da supervisão na formação do psicólogo clínico, ao discutir os resultados de uma pesquisa em que investigou os aspectos referentes ao ensino e a formação de psicoterapeutas. Sendo o principal instrumento a análise na grade curricular, destacam-se os aspectos referentes aos programas das disciplinas de psicoterapia principalmente quanto: a teoria, a técnica e a prática.

De modo geral, os textos que compõem a segunda parte da obra, formam um rico material de apoio em cursos que tratam tanto da importância da atividade de pesquisa para o desenvolvimento social, e até mesmo para a própria Psicologia Escolar como campo de pesquisa científica em Psicologia. Além, é claro, de cursos de pós-graduação nesta área, uma vez que os textos também demonstram ser importantes exemplos de atividades em Psicologia Escolar. Além disso, a referida obra pode, com toda certeza, ser considerada como um abrangente apanhado de pesquisas sobre o ensino de Psicologia e é uma contribuição relevante para esta área do conhecimento psicológico, que através do formato de livro passa a figurar em um contexto com maiores possibilidades de acesso ao público em geral.

Dreyf de Assis Gonçalves Mestrando em Psicologia Escolar

- PUC-Campinas - Bolsista CNPq

Endereço: Rua Pimenta Bueno, 499, Belém - São Paulo-SP CEP 03060-000

Telefone: (Oxxll) 6695-9995 e-mail: zordan@Starmedia.com dreyj@base.com.br 